\title{
Measurement of Tourism Industry-Ecological Environment Coupling Degree and Management and Control Measures for Tourism Environment: A Case Study of Henan Province, China
}

\author{
Yan Fei Shen \\ School of Construction Engineering, Sanmenxia Polytechnic, Sanmenxia 472000, China \\ $†$ Corresponding author: Yan Fei Shen; shyf213@163.com
}

\section{Nat. Env. \& Poll. Tech. Website: www.neptjournal.com \\ Received: 24-02-2020 \\ Accepted: 20-04-2020 \\ Key Words: \\ Tourism industry; \\ Ecological environment; \\ Coupling degree; \\ Environmental \\ management}

\begin{abstract}
The tourism industry has the largest scale of economic activities worldwide with the most powerful development momentum but has generated a negative effect on the ecological environment. The development of the tourism industry is a precondition and guarantee of eco-environmental optimization, and a harmonious ecological environment is an important dynamic support for the growth of tourism economy, making them mutually associated with evident coupling characteristic. In this study, related literature regarding the tourism industry and eco-environmental protection of developed countries in Europe and America were first reviewed, and tourism industry-ecological environment coupling model was constructed using Henan Province, China, as a case study. The coupling degrees in Henan Province during 2013-2018 were measured, and a comparative analysis of the spatial changes in tourism industry-ecological environment coupling degrees of 18 prefecture-level cities in Henan in 2013 and 2018 was conducted. Results showed that the order degree of the tourism industry in Henan Province maintained a rising trend during 2013-2018, whereas that of the ecological environment exhibited a fluctuating trend. The overall tourism industry-ecological environment coupling of 18 prefecture-level cities in Henan Province enhanced in 2013 and 2018, where the coupling degrees in Zhengzhou, Nan yang, and Luoyang presented an outward radiation trend from high to low. The study results serve as significant reference values for revealing the spatial-temporal evolution characteristics of the ecological environment and the tourism industry and completing the research regarding the coordinated development of the tourism industry and ecological environment.
\end{abstract}

\section{INTRODUCTION}

As an industry highly depending on resources and environment, the tourism industry is attached to benign eco-environmental and economic development. The tourism industry has become the main means of improving economic development in various areas. Whether the tourism industry can achieve sustainable development relies on eco-environmental quality. Various contradictions have continuously emerged with the continuous development of the tourism industry. Although the economy is uplifted, environmental contradictions are increasingly becoming prominent, thereby leading to the imbalance between the tourism industry and ecological and environmental development and harming the developmental relationships among regional economy, tourism industry, and ecological environment. The tourism industry can be well developed mainly because it exerts an enormous driving effect on economic development and has green, environmentally friendly, low-pollution, and low-carbon advantages, thereby facilitating environmental protection. However, some regions blindly transform, utilize, and conquer nature to improve the regional economy with the increasing regional tourism competition, thereby contributing to the growth of the tourism industry and economy to a certain degree but posing unrecoverable damage to the ecological environment.

Henan Province is a province with a large population and developed tourism industry in China. As shown in Fig. 1 , the numbers of domestic and foreign tourists that stayed overnight in Henan Province during 2007-2018 present a fluctuating growth trend. Considering that Henan Province has invigorated the development of tourist destinations, the quantity and quality demands of demand subjects for tourist environment are and the pressure imposed by various subject demands for tourist environment is gradually elevated. The scale effect of tourist destinations has resulted in the increasing reliance of destinations for complicated infrastructures, frequent occurrence of tourism disasters, and gradually aggravating chain reaction of disasters. However, the tourism industry does not exert a destructive effect on the environment, and the blind pursuit of the benefits of tourist economy will seriously impact the eco-environmental 
quality of tourist destinations, such as water pollution, air pollution, noise pollution, and damage of soil and vegetation caused by tourist activities. The eco-environmental system is extremely difficult to recover when it is destructed because of its fragility and its recovery requires a certain cycle. The tourism industry is strongly associated with the ecological environment, and the degradation of eco-environmental quality will certainly influence the sustainable development of the tourism industry. Therefore, the tourism industry and eco-environmental system are mutually promoted and contradicted, and a better understanding of the tourism industry-ecological environmental coupling degree provides important realistic values.

\section{PAST STUDIES}

With the continuous improvement of the social and material standards of living, mass tourism activities have become increasingly frequent because of the continuous expansion of tourism size, and the relationship between tourism and environment becomes increasingly close. Studies regarding the relationship between tourism and the environment in foreign developed countries can be traced back to the 1920s. The literature investigating the tourism industry and the ecological environment is provided as follows. Stankey (1981) believed that the number of received tourists within a certain time should be maintained at a moderate level to ensure the environmental quality of tourist destinations, and he divided the tourism environmental capacity into biological, cultural, psychological, and management capacities. Hunter (2002) assumed that the development of the tourism industry may generate a far-reaching influence on the local environment, combined sustainable tourism with the concept of ecological footprint, and proposed all types of concepts of "tourism ecological footprint" and some potential applications. Gössling et al. (2015) evaluated the total use amount of global resources by the tourism industry, indicated that the overall resource consumption in the tourism industry might increase by $92 \%$ (water)-189\% (land use) from 2010 to 2050, and stated that the resource input should be increased to maintain the global tourism system, exerting an important effect on the ecological environment. Ying (2015) defined tourism environment, analyzed the influences of tourism development on water resources, soil, vegetations, and landscapes, and proposed the main protective measures for the tourism industry. Dann et al. (2013) surveyed the potential economic effects of climate change on the related tourism industry. The results showed that the sea level rise during windstorms will impact the tourism infrastructure construction, especially for countries with marine environment. Scott et al. (2010) discussed how global tourism industries can complete their quotas in the aspects of energy conservation and emission reduction. The results indicated that whether emission reduction can be successfully realized depends on the changes in major policies and practices of airline businesses to a great extent. Sun et al. (1988) reviewed the influences of the Australian tourism industry on the environment, especially on vegetations and soil. The results showed that tourism activities might generate adverse effects on the values of Australian natural and seminatural resources when they are improperly

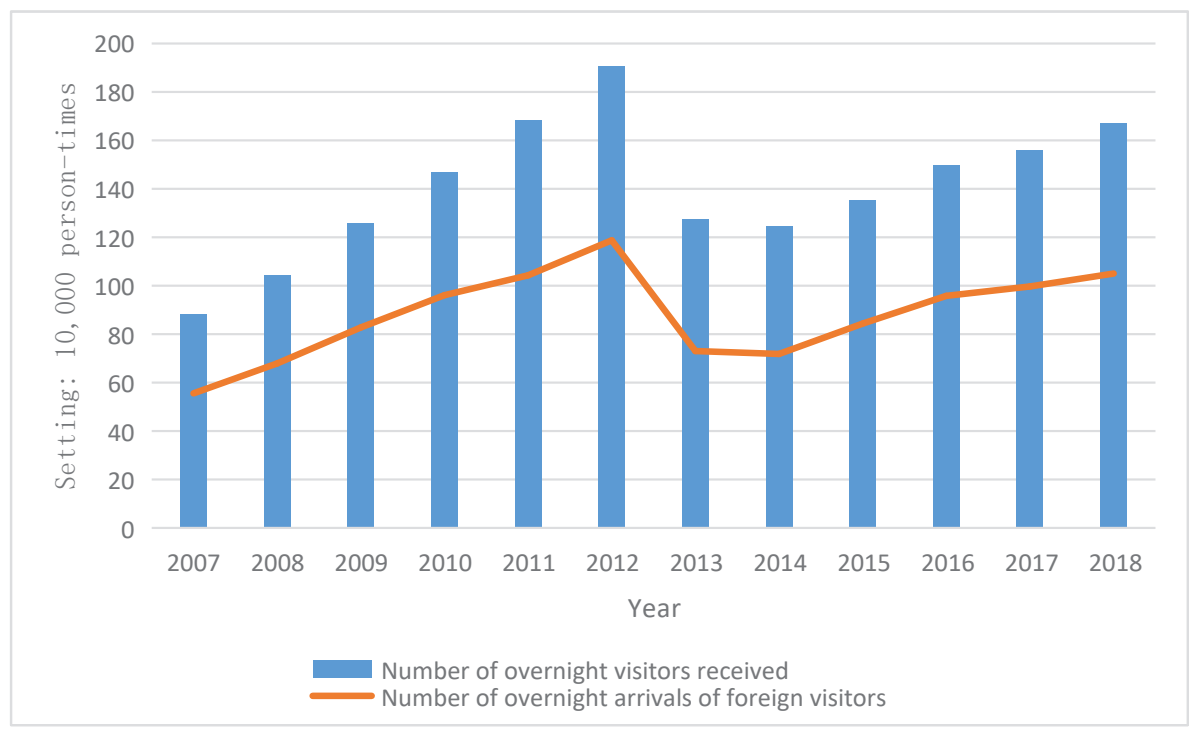

Fig. 1: Numbers of domestic and foreign tourists that stayed overnight in Henan Province during 2007-2018. 
managed, and the quantitative relationship between tourism activities and environmental influence of main vegetations should be determined in subsequent studies. Kytzia et al. (2011) investigated Alps Davos tourist destination and indicated that many successful tourist destinations in highly populated areas in Central Europe experience the problem of approaching the growth potential limit. The results showed that low land utilization efficiency induced by the tourism industry can be solved by strengthening the space planning, architectural design, and facility management. Perch-Nielsen et al. (2010) studied the increasing greenhouse gas intensity caused by the added value of Swiss tourism industry. The results showed that the greenhouse gas emission in Swiss tourism industry is more than four times of the average economic level in Switzerland, and a mitigation plan under the background of preventing the dangerous climate change is proposed. Qiu et al. (2017) calculated and decomposed the $\mathrm{CO}_{2}$ emission in China's tourism industry, discussed its evolution and distribution characteristics on the basis of tourism-ecological efficiency ratio, and used a regression model to analyze the influencing factors. The results indicated that the $\mathrm{CO}_{2}$ emission in China's tourism industry remarkably increases, and the main factors influencing the economic benefits of the tourism industry are scale effect, structural effect, technological effect, and environmental regulation. Reilly et al. (2010) suggested that transportation consumes the maximum energy in the tourism system and proposed transferring tourists through transportation with energy-saving mode to improve the ecological efficiency of tourist traffic. Dwyer et al. (2010) estimated the greenhouse gas emissions of Australian tourism industry and its related activities. The results showed that the tourism industry accounts for $3.9 \%-5.3 \%$ of the total industrial greenhouse gas emissions in Australia. Surugiu et al. (2012) investigated the influences of the tourism industry on $\mathrm{CO}_{2}$ emissions using the economic and environmental data of Romania and proposed several measures for the tourism industry to reduce $\mathrm{CO}_{2}$ emissions. Taking Nepal as an example, Rabindra et al. (2019) evaluated the short-and long-term relationships among the number of tourists, per capita economic output, emission, energy consumption, and capital formation and indicated that energy consumption generates a negative effect on tourist arrivals and more attention should be paid to energy efficiency and energy diversity. Zhang et al. (2019) discussed the associations among the $\mathrm{CO}_{2}$ emissions, actual GDP, unrenewable and renewable energy sources, and tourism industry in 10 Northeast and Southeast Asian countries during 1995-2014 and indicated that the development of the tourism industry will result in environmental degradation. The studies regarding the tourism industry and ecological environment conducted by domestic and foreign scholars have largely shifted from qualitative analysis to quantitative analysis with the emergence and continuous expansion of the tourism industry at global scope. Scholars have emphasized the eco-environmental pollution effect of the tourism industry, where many of them have conducted studies on tourism environmental carrying capacity, but studies on the coupling and coordinated development of the tourism industry and ecological environment are rare. In this study, the interaction and mutual influence between the tourism industry and the ecological environment and their coupling attribute were analyzed using Henan Province, China as an example. The coupling degree was explored, and pertinent policy suggestions were proposed to analyze the coordinated development laws of the tourism industry and ecological environment and predict their evolution trends. This study provides a scientific basis for the coordinated development between the tourism industry and the ecological environment in China

\section{MODEL INTRODUCTION AND DATA DESCRIPTION}

\section{Tourism Industry-Ecological Environment Coupling Model}

Order degree of systems: Considering tourism and environmental subsystems $S_{j}, j \in[1, k]$ investigated in this study, the order parameter during their development process is set as $e_{j}=\left(e_{j 1}, e_{j 2}, \cdots, e_{j n}\right)$, where $n \geq 1, \beta_{j i} \leq e_{j i} \leq \alpha_{j i}, i \in[1, n]$. Without loss of generality, the assumption is that the greater the value of $e_{j 1}, e_{j 2}, \cdots, e_{j l}$, the higher the order degree of the system, otherwise, the lower the order degree; The greater the value of $e_{j l+1}, e_{j l+2}, \cdots, e_{j n}$, the lower the order degree, otherwise, the higher the order degree.

The tourism-environment coupling model includes the tourism industry subsystem and ecological environmental system. The order parameter in the development process of the tourism industry system is $e_{1}=\left(e_{11}, e_{12}, \cdots, e_{1 n}\right)$. Based on the concept of order degree of the system, the order degree of order parameter component $e_{1 j}$ of the tourism industry subsystem is defined as follows:

$$
u_{1}\left(e_{1 i}\right)=\left\{\begin{array}{c}
\frac{e_{1 i}-\beta_{1 i}}{\alpha_{1 i}-\beta_{1 i}}(i=1,2, \cdots l) \\
\frac{\alpha_{1 i}-e_{1 i}}{\alpha_{1 i}-\beta_{1 i}}(i=l+1, l+2, \cdots n)
\end{array},\right.
$$

Where $\alpha_{1 i}$ and $\beta_{1 i}$ denote the maximum and minimum values of the $i$ (th) index of the tourism industry subsystem, respectively. On the basis of this definition, $u_{1}\left(e_{1 i}\right) \in[0,1]$ can be known through normalization, and the greater the value, the greater the contribution of $e_{1 i}$ to the order degree of the tourism industry subsystem. 
The total contribution of the order parameter to the order degree of tourism industry subsystem is realized through the ensemble method of $u_{1}\left(e_{1 i}\right)$, and a method commonly used linear weighting method, as shown in Formula (2).

$$
u_{1}\left(e_{1}\right)=\sum_{i=1}^{n} \omega_{u 1}\left(e_{1 i}\right)\left(\omega \geq 0, \sum_{i=1}^{n} \omega=1\right),
$$

Where $\omega$ is the index weight. The order degree of the tourism industry subsystem is $u_{1}\left(e_{1}\right) \in[0,1]$, and the greater the value of $u_{1}\left(e_{1}\right)$, the higher the contribution of the order parameter $e_{1}$ of the tourism industry subsystem to order degree of the system. Otherwise, the higher the order degree of the tourism industry subsystem, the lower the order degree.

The order parameter during the development process of the eco-environmental subsystem is set as $e_{2}=\left(e_{21}, e_{22}, \cdots\right.$, $e_{2 i}$ ). Similar to the calculation method of the order degree of the tourism industry subsystem, the order degree of parameter component $e_{2 i}$ of the eco-environmental subsystem can be obtained as $u_{2}\left(e_{2 i}\right)$, and $u_{2}\left(e_{2 i}\right) \in[0,1]$.

Synergy degree of systems: The order degrees of the tourism industry and eco-environmental subsystems at the initial time $t_{0}$ are set as $u_{1}^{0}\left(e_{1}\right)$ and $u_{2}^{0}\left(e_{2}\right)$, respectively. When the systems evolve to time $t_{l}$, the order degrees of the tourism industry and eco-environmental subsystems are $u_{1}^{1}\left(e_{1}\right)$ and $u_{2}^{1}\left(e_{2}\right)$, respectively. When $u_{1}^{1}\left(e_{1}\right) \geq u_{1}^{0}\left(e_{1}\right), u_{2}^{1}\left(e_{2}\right) \geq u_{2}^{0}\left(e_{2}\right)$ simultaneously hold, then the tourism industry and ecological environment systems are under synergistic development, and their synergistic degree model is expressed as:

$$
c=\operatorname{sig}(\bullet) \sqrt{\left|u_{1}^{1}\left(e_{1}\right)-u_{1}^{0}\left(e_{1}\right)\right|\left|u_{2}^{1}\left(e_{2}\right)-u_{2}^{0}\left(e_{2}\right)\right|},
$$

where,

$$
\operatorname{sig}(\bullet)=\left\{\begin{array}{c}
1, u_{1}^{1}\left(e_{1}\right) \geq u_{1}^{0}\left(e_{1}\right) \quad u_{2}^{1}\left(e_{2}\right) \geq u_{2}^{0}\left(e_{2}\right) \\
-1, u_{1}^{1}\left(e_{1}\right)<u_{1}^{0}\left(e_{1}\right) \quad u_{2}^{1}\left(e_{2}\right)<u_{2}^{0}\left(e_{2}\right)
\end{array} .\right.
$$

As shown in Formulas (3) and (4), a high degree of synergy can be only achieved when the tourism industry and eco-environmental subsystems are under the orderly state. The entire tourism industry and eco-environmental subsystems cannot achieve a good coordinated state or may not be synergistic at all when the order degree of one subsystem is immensely elevated and that of the other is slightly elevated or declined.

\section{Data Description}

No unified standard is used for the selection of evaluation indexes related to the coupling development of tourism industry and eco-environmental systems. Therefore, the factors influencing the coordinated development of tourism industry and eco-environmental were screened in this study, and an evaluation index system about their coupling and coordinated development was constructed following the abovementioned methods and principles and referring to related literature (Table 1). All statistical data were obtained from the Henan Statistical Bureau website, Henan Statistical Yearbook, and Yearbook of China Tourism Statistics. The investigated period ranged from 2012 to 2018, the investigated objects were Henan Province and 18 of its subordinate prefecture-level cities, and the data in the nearest year were used for individual missing data.

Table 1: Index system of coupling and coordinated development between the tourism industry and the ecological environment.

\begin{tabular}{|lll|}
\hline System & Index & Unit \\
\hline \multirow{2}{*}{$\begin{array}{l}\text { Tourism industry } \\
\text { subsystem }\end{array}$} & Total number of tourists & 10,000 people \\
& Number of domestic tourists & 10,000 people \\
& Number of inbound tourists & 10,000 people \\
& Total tourism revenue & 100 million yuan(RMB) \\
& Ratio of tourism output value to the tertiary industry & $\%$ \\
& Park area & Number \\
& Green coverage & Hectares \\
& Industrial waste gas emission & Hectares \\
Eco-environmental & Industrial wastewater discharge & 100 million tons $/ \mathrm{m}^{3}$ \\
subsystem & Urban domestic sewage discharge & 100 million tons \\
& Treatment rate of domestic sewage & 100 million tons \\
& Harmless treatment rate of household waste & $\%$ \\
& Comprehensive utilization rate of industrial solid wastes & $\%$ \\
\hline
\end{tabular}




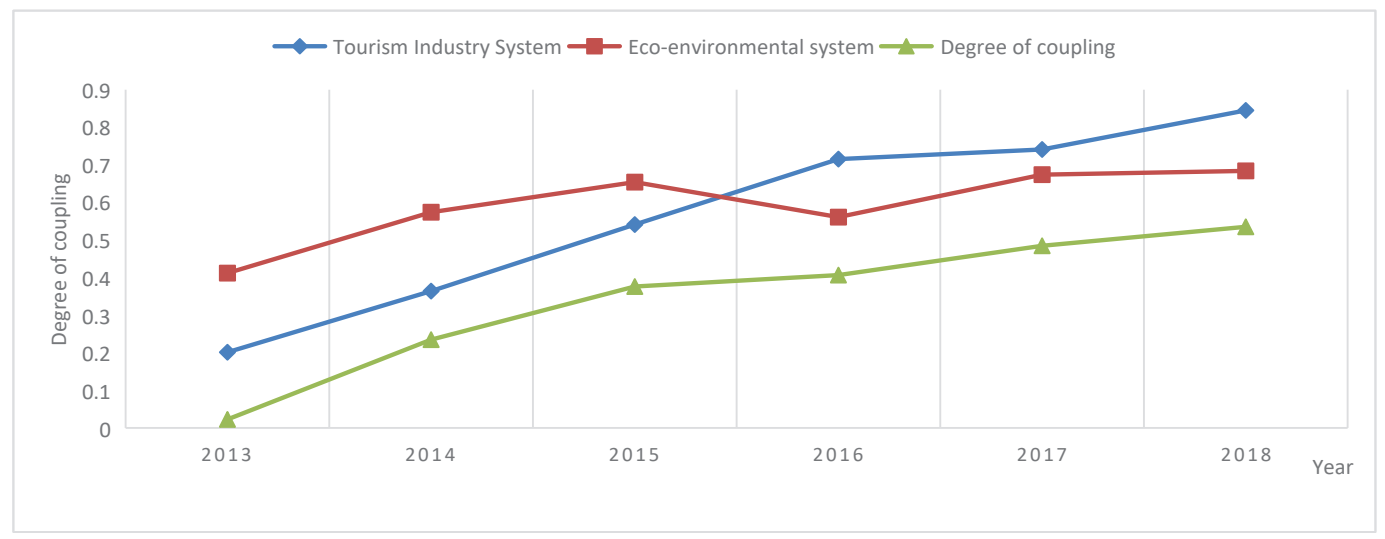

Fig. 2: Tourism industry-ecological environment coupling degree in Henan Province during 2012-2018.

\section{RESULT ANALYSIS}

\section{Tourism Industry-Ecological Environment Coupling Results in Henan Province During 2012-2018}

As shown in Fig. 2, the comprehensive development level of Henan's tourism industry during 2013-2018 maintained a rising trend, where the order degree of the tourism industry system increases every year. Since 2013, the development of the tourism economy in Henan Province changed every day. Positive fiscal policies were used by persisting government-led development strategies, including completely developing the financial sector and positively participating in tourism development planning. The tourism infrastructure construction was effectively managed under the effect of governmental investments, and positive fiscal policies were used to cultivate the tourism industry into a pillar industry. An important orientation was determined, that is, cultivating the tourism industry into a strategically important pillar industry and constructing it into a large province with prosperous tourism industry because Henan issued some positive policies, such as Action Program of Tourism Industry Transformation and Upgrading in Henan Province (2017-2020) and Henan Tourism Industry Development Planning in the 13th FiveYear Plan. Compared with the sustainable development of the tourism economy, the ecological environment presented a fluctuation tendency of "first rising, declining, and rising again," and the growth trend was slow. The eco-environmental level in Henan Province was slowly developing and its eco-environmental carrying capacity experienced great pressure under the strategic background of the "Rise of Central China" implemented in Henan Province in recent years and the social background characterized by economic rise and continuous advancement of industrialization and urbanization in addition to the fragility of the ecological environment itself and frequent occurrence of natural disasters. The tourism industry-ecological environment coupling

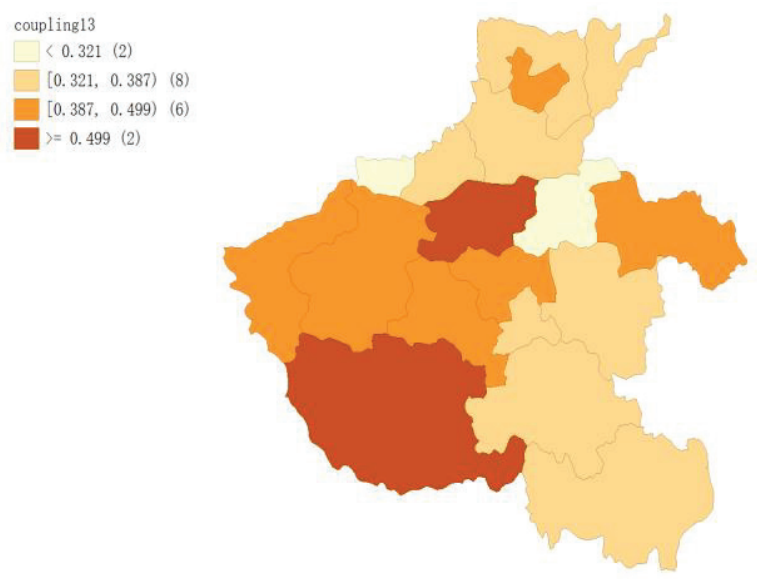

Fig. 3: Tourism industry-ecological environment coupling degree of prefecture-level cities in Henan Province in 2013. 
degree in Henan Province increased from 0 to 0.535 , the coupling grade gradually developed from low coupling degree to high coupling degree, and the entire system developed toward an increasingly orderly direction, suggesting that their correlation become increasingly close. However, the growth trend of coupling degree was slow, indicating that the rapid development of tourism economy in Henan Province during 2015-2018 generated a certain impact on the ecological environment, thereby relatively weakening their coupling relation.

\section{Tourism Industry-Ecological Environment Coupling Results of Prefecture-Level Cities in Henan Province}

As shown in Figs. 3 and 4, the tourism industry-ecological environment coupling of 18 prefecture-level cities in Henan Province improved in 2013 and 2018. The increasing trend of the comprehensive level of the tourism industry in the18 prefecture-level cities extremely accorded with the development status of Henan's tourism industry in recent years. The comprehensive development levels of the tourism economy in individual regions increased decreased in some years, but the fluctuation range was small. Subsequently, the levels increased again and became better, indicating that the comprehensive levels of the tourism economy in the regions maintained a continuous development tendency. The comprehensive development index of Henan's tourism industry had evident spatial differences, and development differences were found between the southern regions and northern prefecture-level cities. The coupling degree in the central region was high, regions with high development index of the tourism industry were mostly concentrated in Zhengzhou, Luoyang, and Nan yang, and the spatial shift of comprehensive tourism development was prominent, reflecting the fierce competitive development status of the tourism economy in these prefecture-level cities.

\section{MANAGEMENT AND CONTROL MEASURES FOR TOURISM ENVIRONMENT}

\section{Adjust the Tourism Industry Structure and Realize Environmentally Friendly Development Mode}

Ecological environment is a fundamental guarantee for realizing the sustainable development of the tourism economy and constitutes a hard-won tourism resource itself. Although the tourism industry is recognized as "green industry" and "smoke-free industry" with relatively minor direct pollution to the ecological environment, various eco-environmental problems will still occur when the economy is blindly pursued while the eco-environmental carrying capacity is ignored. The traditional extensive tourism development mode should be shifted into the green and low-carbon intensive direction in the future to realize the transformation and upgrade of the tourism industry. First, the support structure of tourism sectors should be optimized and ecological tourism services, such as recreational tourism, sightseeing tour, rural tourism, and life cultivation and health preservation tourism, should be vigorously developed. The tourism industry structure should be actively adjusted to promote the transition of tourist attractions from a traditional sightseeing type into complex functions and realize the integrative development of the tourism industry with other types of businesses, such as ecological agriculture and industry. A batch of tourism service enterprises with low energy consumption and minimal pollution should be introduced, cultivated, and integrated into the entire tourism activity to enhance Henan's tourism industry.

2013.

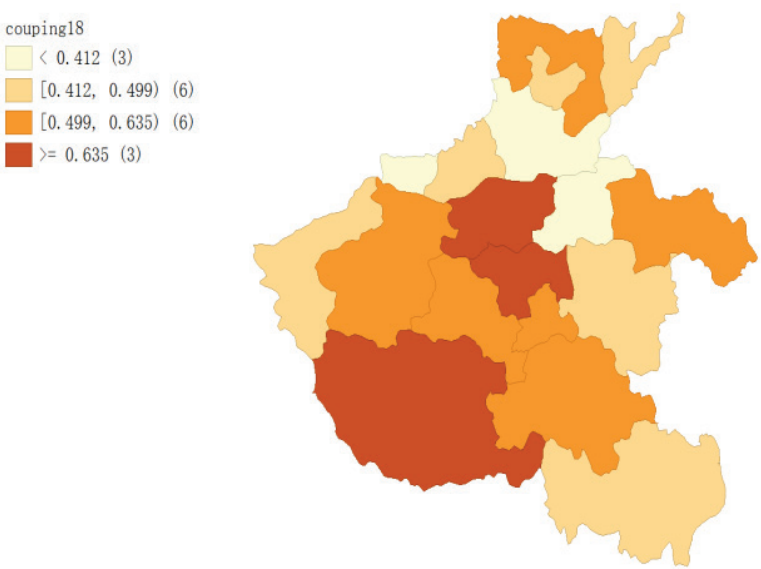

Fig. 4: Tourism industry-ecological environment coupling degree of prefecture-level cities in Henan Province in 2018. 


\section{Realize the High Matching Ratio Between Tourism Development Speed and Environmental Carrying Capacity}

Henan Province owns abundant tourism resources, and unique tourism landscapes provide power for its tourism development. With the gradually elevated governmental emphasis on the tourism industry, the popularity of Henan tourism industry rapidly increases. However, the high tourist population pressure generates a certain influence on its ecological environment, and the development scale of tourism economy exceeds the speed of eco-environmental protection and construction, which is unfavourable to its overall coordinated development. The concept of sustainable development should be clarified and the tourism development should be facilitated with high-quality and strict requirements. High attention should be paid to resource protection and development. The number of tourists should be prevented from exceeding the upper limit of environmental capacity to reduce eco-environmental destruction. Tourist attractions should be reasonably planned and arranged, overdevelopment should be strictly prevented, and their development should be integrated with resource protection by strictly following the construction procedures to accelerate the steady development of Henan's tourism industry.

\section{Strengthen the Publicity and Education of Tourism Eco-Environmental Protection}

Human quality and concept are of great importance to the ecological environment, and ecological civilization construction cannot be separated from the extensive participation of the social public. The joint participation of governmental sectors, tourism enterprises, tourists, and local residents is necessary to promote the tourism of ecological civilization. The publicity and education on eco-environmental protection in tourism activities should be promoted by the social public, including tourism management staff, tour guides, hotel and restaurant service staff, tourists, and local residents. The awareness of tourism management staff and emphasis on eco-environmental protection should be enhanced, and the training of environmental management and protection skills of tourist attractions should be strengthened. Tour guides should be encouraged to convey environmental protection knowledge or ecological ethics to tourists when introducing and interpreting natural landscapes and remind tourists in practicing civilized tourism behaviours toward the ecological environment. For tourism service staff in hotels and restaurants, the common sense of eco-environmental protection should be popularized among them to create a thick tourism atmosphere of nature-loving, ecological protection, and civilized tourism.

\section{Explore and Establish A Tourism Ecological Compensation Mechanism}

Henan Province has numerous sightseeing places, such as mountains, rivers, lakes, forests, and natural heritages. The destruction of the ecological environment will certainly impact the sustainable development of the tourism industry. Henan Province should positively explore and immediately establish a tourism ecological compensation mechanism from province to cities and counties, especially for those sightseeing places with natural landscapes. The government can complete the evaluation and compensation work related to ecological compensation through various means, such as taxes, fiscal transfer, and policy support. The tourism ecological compensation is for the compensation of eco-environmental factors and should aim to realize the compensation for residents in sightseeing places, tourism eco-environmental management staff, and defenders. A comprehensive and long-term effective tourism ecological compensation mechanism can only be established when human compensation is realized to achieve the coordinated development between the tourism economy and ecological environment.

\section{CONCLUSION}

As an industry highly relying on resources and environment, the tourism industry is closely attached to the benign development of ecological environment and economy. However, environmental conflicts caused by the tourism industry are increasingly prominent, thereby leading to the imbalance between the tourism industry and economic and environmental development and harming the developmental relationships among regional economy, tourism industry, and ecological environment. In this study, the tourism industry-ecological environment coupling model was constructed using Henan Province, China as an example. The tourism industry-ecological environment coupling degrees in Henan Province during 2013-2018 were measured, and a comparative analysis of the spatial changes in the tourism industry-ecological environment coupling degrees of 18 prefecture-level cities in Henan Province in 2013 and 2018 was conducted. The results showed that the order degree of Henan's tourism industry maintained a rising trend during 2013-2018, whereas that of its ecological environment displayed a fluctuating trend, and the tourism industry-ecological environment coupling degree improved by a small margin. The comparison of tourism industry-ecological environment coupling degrees of 18 prefecture-level cities in Henan Province in 2013 and 2018 showed that the coupling degrees in Zhengzhou, Nan yang, and Luoyang presented an outward radiation trend from high to low. The policy measures proposed include adjusting the tourism industry structure, realizing the high matching ratio 
between the tourism development speed and environmental carrying capacity, strengthening the publicity and education of tourism eco-environmental protection, and exploring and establishing a tourism ecological compensation mechanism. An in-depth study should be conducted to perfect the measurement index system of tourism industry-ecological environment coupling degree. A comprehensive evaluation model should be utilized to quantitatively analyze the tourism and ecological environment and the evolution of spatial coordinated development between the tourism industry and the ecological environment.

\section{ACKNOWLEDGEMENT}

This work was supported by the Henan science and technology research project (192102310524).

\section{REFERENCES}

Dwyer, L., Forsyth, P., Spurr, R. and Hoque, S. 2010. Estimating the carbon footprint of Australian tourism. Journal of Sustainable Tourism, 18(3): 355-376.

Dann, P. and Chambers, L. 2013. Ecological effects of climate change on little penguins Eudyptula minor and the potential economic impact on tourism. Climate Research, 58(1): 67-79.

Gössling, S. and Peeters, P. 2015. Assessing tourism's global environmental impact 1900-2050. Journal of Sustainable Tourism, 23(5): 639-659.

Hunter, C. 2002. Sustainable tourism and the touristic ecological footprint. Environment, Development and Sustainability, 4: 7-20.
Kytzia, S., Walz, A. and Wegmann, M. 2011. How can tourism use land more efficiently? A model-based approach to land-use efficiency for tourist destinations. Tourism Management, 32(3): 629-640.

Perch-Nielsen, S., Sesartic, A. and Stucki, M. 2010. The greenhouse gas intensity of the tourism sector: The case of Switzerland. Environmental Science \& Policy, 13(2): 131-140.

Qiu, P., Fang, P., Yang, T. and Zhu, B. 2017. Tourism eco-efficiency measurement, characteristics, and its influence factors in China. Sustainability, 9(9): 1634.

Reilly, J., Williams, P. and Haider, W. 2010. Moving towards more eco-efficient tourist transportation to a resort destination: The case of Whistler, British Columbia. Research in Transportation Economics, 26(1): 66-73.

Rabindra, N., Irsyad, M. I. and Nepal, S. K. 2019. Tourist arrivals, energy consumption and pollutant emissions in a developing economy-implications for sustainable tourism. Tourism Management, 72: 145-154.

Surugiu, C., Surugiu, M. R., Zelia, B. and Dinca, A. I. 2012. An input-output approach of $\mathrm{CO}_{2}$ emissions in tourism sector in post-communist Romania. Procedia Economics and Finance, 3: 987-992.

Scott, D., Peeters, P. and Gössling, S. 2010. Can tourism deliver its "aspirational" greenhouse gas emission reduction targets. Journal of Sustainable Tourism, 18(3): 393-408.

Sun, D. and Walsh, D. 1998. Review of studies on environmental impacts of recreation and tourism in Australia. Journal of Environmental Management, 53: 323-338.

Stankey, G.H. 1981. Integrating wildland recreation research into decision making: Pitfalls and promises. Recreation Research Review, 9(1): 31-37.

Ying, A.N. 2015. Tourism Development and Ecological Environment Protection. Journal of Landscape Research, 7(01): 43-44.

Zhang, S. and Liu, X. 2019. The roles of international tourism and renewable energy in the environment: New evidence from Asian countries. Renewable energy, 139: 385-394. 